\title{
EFFECTIVE TORTURE PREVENTION
}

Richard Carver and Lisa Handley

Published in:

Research handbook on torture: Legal and medical perspectives on prohibition and prevention

[ISBN: 9781788113953] / edited by Malcolm D. Evans and Jens Modvig (Edward Elgar, 2020).

\section{Introduction}

The prohibition of torture is not only one of the strongest principles of international human rights law; it also has the most detailed underpinning in treaty law, reinforced by the jurisprudence of regional and national courts, and treaty bodies. If a state is genuinely committed to eradicating torture, there is little doubt as to what international law requires it to do. The question, rather, is whether any of these things actually work. The requirements of international human rights law tend to be a combination of broad principle and common sense. They are not usually formulated in response to detailed empirical inquiry, so the detailed prescriptions of the Convention Against Torture (UNCAT) ${ }^{1}$ and its Optional Protocol (OPCAT) ${ }^{2}$ (not to mention the various dicta of the treaty bodies and special procedures) are based on a set of educated guesses.

The findings reported in this chapter are the outcome of a four-year multi-country study conducted by a team of more than 20 researchers, and funded by the Association for Prevention of Torture (APT), a Geneva-based international non-governmental organization. Our research addressed a very specific question: does torture prevention work ${ }^{3}$ We were not seeking to uncover the root causes of torture or the political, economic or social factors associated with its increase or decline. Instead we focused solely on the effectiveness of preventive measures in reducing the incidence of torture. Much thought and practical effort has been expended - by international experts, civil society activists, legislators, and others - in determining what steps governments should take to prevent torture. The outcome of this thought and effort is to be found in the international instruments themselves, primarily the UNCAT and the OPCAT, as well as in the reports and recommendations of

\footnotetext{
${ }^{1}$ Convention against Torture and Other Cruel, Inhuman or Degrading Treatment or Punishment (adopted 10 December 1984, entered into force 26 June 1987) 1465 UNTS 85

${ }^{2}$ Option Protocol to the Convention against Torture and Other Cruel, Inhuman or Degrading Treatment or Punishment (adopted 18 December 2002, entered into force 22 June 2006), UNGA Res 57/199

${ }^{3}$ We focused solely on torture or purposive ill-treatment. Other forms of ill-treatment fell beyond the scope of our study.
} 
international, regional and national bodies. Yet no one had actually studied whether the various legal obligations and practical steps actually had any effect in reducing the risk of torture. The APT, which devotes its time and money to promoting these preventive measures, sought an honest answer to this question and funded us to lead an entirely independent scholarly project to give an answer.

Previous academic approaches to the issue of torture prevention fell broadly into three categories. Much of it is legal/normative and the very best of this has been produced by scholars who have also been prominent in implementing these norms through the international system. Secondly, there are a number of country case studies, usually qualitative in approach. These are often helpful in understanding the specific dynamics behind successful torture prevention in a given context, and were useful to us in identifying variables to test in our own research. But they cannot offer generalizable conclusions. Thirdly, political scientists have conducted some large $\mathrm{n}$ quantitative studies, but these have generally focused on questions adjacent to our own research. For example, several scholars have looked at the relationship between ratification of human rights treaties such as the UNCAT and improved respect for human rights (often concluding that treaty ratification has no positive effect). For us, this was the wrong question. We were not interested in the impact of ratification in itself; rather we wanted to know whether practical implementation of the obligations in the UNCAT, for example, would contribute to reducing the risk of torture.

We used two distinct methodological approaches to answer the question "does torture prevention work?". First, in-country research teams carried out detailed qualitative case studies of torture prevention efforts and their impact in 16 countries over a thirty-year period (1985-2014). Secondly, we quantified much of the information collected in order to conduct a statistical analysis to determine if there were any discernable patterns across the 16 countries. We were specifically interested in ascertaining which preventive measures, if any, were most likely be associated with a decrease in the incidence of torture. Once this analysis was completed, we drew on our country examples to illustrate the patterns our examination uncovered.

The results of our analysis indicated that torture prevention does indeed work. The introduction of some specific preventive measures undoubtedly reduced the incidence of torture in the countries we studied. We also found that some of the preventive steps we looked at were more effective at reducing torture than others across these countries.

Of the four clusters of preventive measures we considered, clearly the most important were the safeguards in place in the first hours and days after arrest, particularly promptly notifying the family of the arrest, informing the detainee of the right to a lawyer (which the detainee then exercises), 
and providing a medical examination shortly after detention. The second most important set were those related to the prosecution of torturers, especially that torture complaints are lodged and investigated, that conviction rates for torture are comparable to those of other serious crimes, and that no amnesty or pardons are granted to torturers. Also important were measures related to monitoring, particularly that detainees are interviewed and that sanctions are not brought against monitors or those who cooperate with them. The least effective set of preventive measures we examined were those related to complaints bodies, with the caveat that complaints bodies that feed directly into an investigative or prosecutorial authority are more effective in reducing torture than those that do not.

Our analysis uncovered another important finding: practice is far more important than law at reducing the incidence of torture. As we began to collect information, it became quite evident there is often a gap between practice and law - that is, there is often a failure to fully implement and enforce legislation that has been enacted. We felt it was important to note both the state of the law and the degree to which it was being enforced in any given year for each country. Our analysis confirmed the gap, and indicated that the size of the gap varies depending on the specific set of preventive measures, with it being the widest between prosecution law and practice (ie, although torture is illegal in all of the countries included in our research, torturers are rarely tried or, when tried, seldom convicted in these countries).

\section{How do we know this?}

As noted above, our study encompassed 16 countries over a 30 -year period. The countries were selected to provide geopolitical diversity. Given that a 30-year time span was covered, most countries had a variety of different experiences of both the prevalence of torture and the existence of preventive mechanisms or measures. Additional pragmatic selection criteria included the availability of experience and high quality researchers, as well as safe access. One country had to be replaced at an early stage because of risks to the researcher. The final list of countries was: Argentina, Chile, Ethiopia, Georgia, Hungary, India, Indonesia, Israel, Kyrgyzstan, Norway, Peru, Philippines, South Africa, Tunisia, Turkey, and the United Kingdom. In addition to producing qualitative case studies for most of these countries, we also generated a quantitative database. We identified 66 possible preventive mechanisms and for each country, for each year, we coded whether the mechanism was fully present, partially present, or absent. We then constructed eight indices, two for each of the four clusters of preventive mechanisms studied: detention law and practice; prosecution law and practice; complaints law and practice; and monitoring law and practice. The higher a country scored on an index, the more preventive mechanisms were in place. 
Our independent variables were drawn from the broad array of legal standards, binding and nonbinding, and recommendations from human rights bodies.

The first cluster of preventive measures was derived from the UNCAT and primarily directed at criminalizing torture and holding its perpetrators accountable through criminal law. Article 2(1) of the Convention makes it clear that the overarching purpose of the treaty is prevention. That is, the criminalization and effective investigation of acts of torture, and the prosecution or extradition of alleged torturers are aimed at preventing the further incidence of torture.

Secondly, the OPCAT exemplifies the role of monitoring bodies in preventing torture, with its requirement that states parties establish their own national preventive mechanism (NPM) to work in concert with UN Subcommittee on Prevention of Torture (SPT), both of which enjoy powers to visit places of deprivation of liberty. An external visiting body has existed in Europe for nearly three decades, under the European Convention on the Prevention of Torture,${ }^{4}$ while many countries already have domestic bodies empowered to conduct such visits.

Thirdly, complaints bodies are seen by many as another important preventive mechanism. ${ }^{5}$ Independent complaints mechanisms in this sense are usually understood to be something distinct from prosecutorial bodies that investigate complaints of torture. They are normally no-cost, semiformal bodies such as ombudsman offices or national human rights institutions.

Finally, campaigners against torture have often argued for the significance of safeguards on arrest and during police detention, when the risk of ill-treatment is likely to be greatest. While there is some overlap with the fair trial protections to be found, for example, in Articles 9 and 14 of the International Covenant on Civil and Political Rights, ${ }^{6}$ these mechanisms tend to be less well protected in international law.

In addition to creating a coding scheme for the presence or absence of preventive mechanisms, we had to adopt a scheme for measuring the incidence of torture. Although countries vary in the both their legal and colloquial definitions of torture, we needed to employ a uniform measure across all 16 countries over the entire 30-year scope of the study. We devised the Carver-Handley Torture

\footnotetext{
${ }^{4}$ European Convention for the Prevention of Torture and Inhuman or Degrading Treatment or Punishment (adopted 26 November 1987, entered into force 1 February 1989) ETS 126

${ }^{5}$ European Committee for the Prevention of Torture and Inhuman or Degrading Treatment or Punishment, CPT Standards, CPT/Inf/E (2002) 1 - Rev. 2015

${ }^{6}$ International Covenant on Civil and Political Rights (adopted 16 December 1966, entered into force 23 March 1976) 999 UNTS 171
} 
Score (CHATS) for this purpose. The CHATS was compiled using a variety of primary and secondary sources. ${ }^{7}$ It is composed of three elements:

- Frequency, scored on a scale of 0 to 3, which measures the degree to which torture within the custodial system is routine and pervasive. Answers range from never (no case of torture) to very likely (torture is systematic, pervasive or routine).

- Geographical spread, scored from 0 to 2, which measures whether torture occurs across the entire jurisdiction of the state (' 2 ') or only in particular regions or areas (' 1 ').

- Severity, scored from 0 to 2 , which measures how severe the treatment is after it has been established that ill-treatment is sufficiently severe to qualify as torture. The CHATS distinguishes torture (' 1 ') from more severe torture (' 2 '). To be clear, when we consider the issue of torture methods, it is important to underline that we are not distinguishing between those that are more or less detectable. Nor are we passing judgment on the scale of pain and suffering endured by any particular victim of torture. Rather, this measure seeks to capture the intent of the state agents who commit torture. Severity is assessed partly in terms of the torture techniques commonly used, but also considers combinations of method, and duration and repetition.

The overall CHATS score combines the three measures on a scale of 0 to 5 . Because CHATS automatically registers a minimum score of ' 3 ' if torture is present (since there must be a score of at least ' 1 ' on each of the three measures), we have corrected for this by assigning a point for severity or geographical spread only when these scores reach more than 1 . the higher level.

The first step in the statistical analysis was to produce bivariate correlations of each of the eight indices with CHATS to determine which of the eight indices were most strongly associated with the incidence of torture. The results are listed in Table 1.

\section{Table 1 about here}

All the correlations are statistically significant, and the signs are all in the expected direction. The higher the correlation (that is, the closer it is to 1.0), the stronger the relationship between the two variables. The correlations in Table 1 indicate that, first, practice is a better predictor of the

\footnotetext{
${ }^{7}$ We used as a starting point the annual reports put out by the US State Department (Human Rights Country Reports) and Amnesty International (Annual Reports) because they are contemporaneous and use the year as their unit of reporting. We supplemented this information with numerous other sources, including contemporaneous reports by different international and domestic human rights organizations, official and unofficial statistics, and extensive interviews with primary sources.
} 
incidence of torture than law (none of the law indices correlates very strongly with CHATS) and secondly, of all the indices, detention practice, with a correlation of -.763 , is the best predictor of the incidence of torture. This is followed by prosecution practice (-.558), and monitoring practice (-.457). Complaints law (-.352) and complaints practice (-.312) have similar correlation coefficients, and come fourth and fifth in order of strength. Prosecution law (-.198) has the lowest correlation with CHATS.

The high correlations between CHATS and several of the indices indicate that at least some sets of potential preventive mechanisms are associated with reducing the incidence of torture. To further explore this, and determine which sets are particularly effective relative to the others, a multivariate statistical analysis is required.

Our database of 480 data points ( 16 countries times 30 years produced a database with 480 countryyears) allows us to test the effectiveness of our eight indices both over time and across countries simultaneously. We also included a set of control variables in our multivariate models to isolate the effects of the preventive mechanisms we are interested in from other broad factors we know from previous research may be related to the level of torture. These control variables included how democratic the country was, whether the country was engaged in international and civil conflict, the level of economic development, and the size of the population at a given time. The results of one of our multivariate analyses are found in Table 2.

\section{Table 2 about here}

This multivariate regression model indicates that detention practice is the only statistically significant preventive factor, with a coefficient of $-.182 .{ }^{8}$ Two control variables are also statistically significant: democracy with a coefficient of -.064 (the more democratic the country, the less likely it is to torture) and population with a coefficient of .429 (the larger the country, the more likely it is to torture). All the regression models that we used underlined the centrality of detention safeguards in practice as the most effective group of preventive measures. ${ }^{9}$ However, for statistical reasons, the multivariate analysis only considers the relative importance of different groups of preventive

\footnotetext{
${ }^{8}$ Although we report the results of one statistical model here, we actually employed a number of different statistical approaches to measure the relative weight of the various preventive indices. Regardless of the approach adopted, detention practice emerged as the single most important set of preventive measures in explaining the incidence of torture. It was consistently statistically significant, the sign of the coefficient was always in the expected direction, and the correlation between detention practice and CHATS was consistently stronger than CHATS and any other index. Clearly good detention practices are key to reducing the incidence of torture.

${ }^{9}$ A full discussion of the multivariate regression models and findings can be found in Carver and Handley, Does Torture Prevention Work?, pp. 57-66.
} 
measures - detention, prosecution, monitoring and complaints, in both law and practice. The bivariate correlations elucidate by demonstrating the strength of the relations between the risk of torture and each specific prevention measure within these groups.

\section{What does this mean for preventing torture?}

The European Committee for the Prevention of Torture (CPT) describes third-party notification, access to a lawyer, and an independent medical examination as the "trinity" of anti-torture safeguards. ${ }^{10}$ While we would avoid the faintly religious terminology, our findings completely concur. Taken together, these three safeguards address an observation of Nigel Rodley's that sums up the collective experience of many anti-torture activists: "torture is a crime and, like many other crimes, is a crime of opportunity." Recalling his work at Amnesty International in the 1970s and 1980s he stated:

We were aware that torture happened to people when they were held at the sole mercy of their captors and interrogators (incommunicado detention). The longer they were denied access to and from the outside world (i.e., to families, lawyers, doctors, courts) the more they were vulnerable to abuse by those wishing to obtain information or confessions from them. ${ }^{11}$

The first element of this protection against incommunicado detention is that someone in the world outside has knowledge that the individual is in custody. The argument for not making such a notification is usually framed in terms of not alerting accomplices or facilitating the destruction of evidence. Yet it is perfectly possible to frame an exception where the right may be overridden, for a limited period, to prevent interference with the investigation; in the United Kingdom, Section 56(2) of the Police and Criminal Evidence Act (PACE) ${ }^{12}$ provides just such an exception.

In most of the 16 countries we studied, there has been significant improvement in third-party notification in recent years, not only because of strengthened legal requirements, but also because of technological developments - the widespread use of cellular phones - that make contact much easier.

\footnotetext{
${ }^{10}$ European Committee for the Prevention of Torture and Inhuman or Degrading Treatment or Punishment, CPT Standards, Strasbourg 2015, CPT/Inf/E (2002) 1 - Rev. 2015

${ }^{11}$ N.S. Rodley, 'Reflections on Working for the Prevention of Torture' (2009) 6 Essex Human Rights Review 1521

12 Police and Criminal Evidence Act 1984
} 
The right to notify a third party may be framed in one of two ways. Sometimes it is a direct obligation on the arresting authority to contact a family member or friend (for example, Kyrgyzstan, South Africa). Otherwise it is a right of the arrested person that they may choose whether or not to exercise (United Kingdom, Norway). The reasoning behind this is that a person may sometimes not want friends or family to know they have been arrested. Yet the second framing is problematic. The Inter-American Court of Human Rights considered the celebrated case of Walter Bulacio from Argentina - where the right to notify is framed as one to be exercised by the suspect, not the police. Bulacio was beaten to death with no opportunity to notify. ${ }^{13}$

The second element is the right of access to a lawyer. As with third-party notification, the argument against this right is that legal access will impede the investigation. Unlike third-party notification, however, this has been elevated to the status of a positive principle in many legal systems, most obviously French criminal procedure (until very recently) with its garde à vue detention. It is this positive exclusion of lawyers in the early stages of detention that has impeded the affirmation of the right to legal counsel as hard international law. Matters are also confused by the fact that where the right to counsel does exist in international law it is as an element of the right to a fair trial rather than the right not to be tortured. While there is clearly an overlap between the two, often the importance of the right to a lawyer may be more to do with physical presence than legal advice. Access to a lawyer as part of the right to a fair trial does not necessarily provide protection at the time of greatest risk in the first hours after arrest. We learned that one of the most effective measures in reducing torture and ill-treatment in England and Wales was the duty solicitor scheme that was introduced pursuant to the Police and Criminal Evidence Act. It was the constant presence of lawyers in and around police custody suites that had the impact, not the legal advice provided. ${ }^{14}$ Similarly, groups of lawyers in Chile organize visits to police stations in the aftermath of social unrest in order to identify and interview those held in detention. ${ }^{15}$

The general pattern in countries we studied was one of increased access to lawyers at an early stage of detention over the past three decades. The problem is often that broadly defined exceptions are provided in law. In the United Kingdom, exceptions under the PACE are determined on a case-bycase basis, but in countries like India and Turkey emergency provisions may deny or delay legal access for whole categories of detainee. Under Israel's Criminal Procedure Code, arrested persons

\footnotetext{
${ }^{13}$ Bulacio v Argentina (2003) Series C no 100

${ }^{14}$ R. Carver, 'United Kingdom' in R. Carver and L. Handley (eds), Does Torture Prevention Work? (Liverpool University Press, Liverpool 2016)

${ }^{15}$ K.F. Neira and P. Engstrom, 'Chile' in R. Carver and L. Handley (eds), Does Torture Prevention Work? (Liverpool University Press, Liverpool 2016)
} 
are guaranteed immediate access to a lawyer; in the Occupied Palestinian Territories, security detainees may have their access to a lawyer delayed for up to 30 days. ${ }^{16}$

The obstacles to realizing this right are considerable and not confined to legally defined exceptions. Deliberate official obstruction is clearly one factor, with one of the most effective methods being not informing an arrested person of their right to a lawyer. We found that as soon as suspects were told of their right to see a lawyer, they were highly likely to exercise it and the incidence of torture was reduced. Authorities can then impede effective exercise of the right in various ways. In Hungary, for example, while lists of lawyers are drawn up by regional bar associations, the actual choice in any given case is made by the police. There is also a tendency to notify lawyers at the last minute - often literally - so that the formal box has been ticked but it is impossible in practice for the lawyer to attend the interview. ${ }^{17}$

In many countries that we studied there were simply not enough lawyers. In Kyrgyzstan, for example, this meant that suspects would often end up being visited by pro-police lawyers unsympathetic to their complaints. In South Africa, it often means that they have no lawyer at all. In many places there is no system of free legal representation, with the result that poor detainees are simply unrepresented.

Our finding that an independent medical examination is an important protection against torture has been well understood for a long time. No doubt this is partly because of the leading role played by the medical profession in the global struggle against torture, resulting in the development of the Istanbul Protocol as a set of sophisticated guidelines for the assessment of medical evidence of torture. ${ }^{18}$ The importance of medical examinations in torture prevention is self-evident, whether these are routine examinations at pre-determined moments (such as entry into custody or transfer between facilities) or exams triggered by a particular event, such as a request from the detainee. The knowledge that a detainee will be routinely examined can act as a deterrent to deliberate illtreatment, while an examination also offers the possibility of identifying medical evidence of torture or other ill-treatment in a timely manner. However, there are several obstacles to effective and independent examinations. Obstruction by the detaining authority is clearly one. In many countries we heard of police preventing proper medical examinations, remaining in the room while the

\footnotetext{
${ }^{16}$ I. Ballas, 'Israel' in R. Carver and L. Handley (eds), Does Torture Prevention Work? (Liverpool University Press, Liverpool 2016)

${ }^{17}$ B. Ivany, A. Kádár and A. Nemes, 'Hungary' in R. Carver and L. Handley (eds), Does Torture Prevention Work? (Liverpool Univeristy Press, Liverpool 2016)

${ }^{18}$ Manual on the Effective Investigation and Documentation of Torture and Other Cruel, Inhuman or Degrading Treatment or Punishment (United Nations, New York and Geneva 2004) HR/P/PT/8/Rev.1
} 
examination took place and demanding to see the medical report, which should of course remain confidential. Although these practices are widespread, they may not be the greatest problem.

In many instances, the only available medical personnel are employees of the detaining authority who cannot be relied upon to act independently. Public healthcare systems are not necessarily a problem. In the UK National Health Service personnel are rightly regarded as independent in the police or prison context. By contrast, the position of the district surgeons in South Africa is a welldocumented example of the conflicts that result. ${ }^{19}$

A further problem is a lack of the specific skills required to identify the signs and symptoms of torture, which are not part of the normal competence of medical personnel. In Turkey, for example, where the medical profession plays a particularly important role in campaigning against torture, there has been a major effort to train personnel in the standards contained in the Istanbul Protocol. Yet it is an uphill struggle, since most of those trained soon end up in other branches of medicine. ${ }^{20}$ A final problem, which has possibly been neglected, is that medical personnel may simply be unsympathetic to torture victims. This was the finding of a survey from India, which discovered that more than half of doctors thought that coercive methods could be justified. ${ }^{21}$

The idea that a person should only be held in a lawfully designated place of detention is obviously fundamental. At the extreme, secret prisons are associated with enforced or involuntary disappearances and are almost inevitably associated with ill-treatment of those held in them, at the very least. A number of such instances could be found in the countries that we studied, including Argentina, Chile, Ethiopia, Indonesia, Peru, and the Philippines. Unfortunately, unlawful detention may also be a consequence of well-intended but poorly-implemented efforts to protect detainees. Kyrgyzstan, for example, has seen a proliferation of secret detention places because of a police backlash against new rules protecting criminal suspects. ${ }^{22}$ Even lawful exercise of police powers, such as random identity checks, can constitute a form of effective "custody" whereby a person never actually enters into a lawful place of detention. For example, in Argentina the police round up urban youth in razzias, while Turkish police conduct ID checks and British police enjoy "stop and search" powers. These can often be the site of ill-treatment, or even torture.

\footnotetext{
${ }^{19}$ P. Gready and J.d. Gruchy, 'District Surgeons in Apartheid South Africa: A Case Study of Dual Obligations' (2003) 7 Health and Human Rights 112-43

${ }^{20}$ K. Altiparmak, R. Carver and L. Handley, 'Turkey' in R. Carver and L. Handley (eds), Does Torture Prevention Work? (Liverpool University Press, Liverpool 2016)

${ }^{21} \mathrm{~J}$. Lokaneeta and A. Jesani, 'India' in R. Carver and L. Handley (eds), Does Torture Prevention Work? (Liverpool University Press, Liverpool 2016)

${ }^{22}$ A. Baijumanova, M. Birk and L. Ismailova, 'Kyrgyzstan' in R. Carver and L. Handley (eds), Does Torture Prevention Work? (Liverpool University Press, Liverpool 2016)
} 


\section{Other detention safeguards}

Another safeguard we found to be of importance is the electronic recording of police interviews with the suspect. The purpose of this is primarily to establish that the interview is conducted in a noncoercive manner. It is essential for this purpose that the entire interview be recorded and, in systems that use this procedure, strict protocols are established governing the conduct of the interview and the storage of the tape or digital file. In our study, the only country that uses electronic interview recording comprehensively is the United Kingdom. Its introduction in the 1980s was prompted by a series of miscarriages of justice involving false confessions, some of them induced by torture. Other countries that we studied only used recording of interviews selectively, which largely undermines their purpose. In Argentina, for example, a judge can order the recording of interrogations in complex cases, but to assist in assessing the evidence, not to protect the suspect. Another problem with how recorded interviews have often worked in practice is the non-availability of electronic records when they are needed - and the same thing applies to closed-circuit video recording of police stations, detention centres and prisons. In almost every country that we studied, video recording, storage and retrieval systems have a quite uncanny failure rate, precisely when they are required to document allegations of abuse. In other words, this only works as a safeguard if there are serious protocols ensuring that recordings will be made and preserved free of interference.

The issue of electronic recording of interviews is closely related to another question, namely the reliance of investigators and prosecutors on confession evidence. This can be seen as a practical cognate of the principle of non-admissibility of evidence derived from torture, as enunciated in article 15 of the UNCAT. We found a clear and strong relationship between reduced reliance on confessions and a decline in the incidence of torture. The purpose of torture is very often to secure a confession or other statement. If this avenue is blocked, or if other alternatives are available, torture will be significantly reduced. Qualitative support for this claim comes in an inverted form from the two post-Soviet countries in our study. With the collapse of the Soviet Union in 1991, Georgia and Kyrgyzstan overnight lost almost all their trained and experienced police investigators. The consequence was a rapid increase in the use of torture since police knew no way of investigating a case other than beating a confession out of someone. Both countries have made some progress in climbing out of that particular hole, with Georgia having undergone a wholesale reform of the police after 2004, with the aim of improving professional standards and rooting out corruption. ${ }^{23}$

\footnotetext{
${ }^{23}$ A. Baijumanova, M. Birk and L. Ismailova, Kyrgyzstan; B. Jikia and M. Shalikashvili, 'Georgia' in R. Carver and L. Handley (eds), Does Torture Prevention Work? (Liverpool University Press, Liverpool 2016)
} 
In our study, only two countries, the United Kingdom and Norway, have made a deliberate decision to end sole reliance on confessions, requiring that they be corroborated by other types of evidence. It is presumably not coincidental that these are also the two most economically developed countries that we looked at, with greater resources to allocate to other avenues of investigation, such as forensic science. However, most of the countries in our study exhibited some shift away from a sole reliance on confession evidence since the 1980s. Usually this appears to have been through the use of electronic surveillance evidence. A South African judge rather theatrically took his cellphone from his pocket to illustrate that most criminals these days now carry a GPS tracking device on their person (although sadly this does not stop the police from torturing anyway). ${ }^{24}$ Government officials in Turkey were proud of the purported benefits of large-scale surveillance of citizens. ${ }^{25}$ These types of evidence are clearly problematic in their own way, but they do appear to have contributed to an understanding that confessions are not the only or the most effective route to criminal convictions.

The move away from the confession as the goal of criminal investigation is intimately bound up with a change in the way that the suspect is questioned by police, away from the interrogation towards the investigative interview. The United Kingdom and Norway have both made this shift in recent years, encouraging interviewing based upon building rapport rather than conflict. Scholars have effectively demonstrated that such an approach is more effective not only in protecting the suspect from physical abuse but also in gathering accurate and useable evidence for the investigators. This applies not only in regular criminal cases, but also in the counter-terrorism investigations that are so often used to argue in favour of "enhanced interrogation." ${ }^{26}$ A clear example in the countries we studied was the case of Anders Behring Breivik, the far-right terrorist who killed 77 people in Norway in 2011. On arrest, Breivik claimed that other "units" were still active, but refused to provide the police with information - precisely the "ticking bomb" scenario often used to justify torture. The Norwegian authorities gave command of the investigation to Asbjorn Rachlew, a police superintendent with a doctorate in psychology who was a leading advocate of the new techniques of investigative interviewing. It was quickly established, without resort to torture or ill-treatment, that there were no more terrorists at large.

\footnotetext{
24 Interview with Judge Vincent Saldanha, Cape Town, 23 July 2014

25 Interview with officials of the Ministry of the Interior, Ankara, 16 January 2013

${ }^{26} \mathrm{~L}$. Alison, S. Giles and G. McGuire, 'Blood from a stone: why rapport works and torture doesn't in "enhanced" interrogations' 7 Investigative Interviewing: Research and Practice 5-23
} 
Rachlew has become one of the principal advocates of investigative interviewing, which he describes as "an operationalization of the presumption of innocence." ${ }^{27}$ In other words, rather than seeking to prove or falsify one particular hypothesis about responsibility for a crime, the purpose is to test a variety of alternative hypotheses. This benefits the suspect, insofar as it is premised upon innocence and precludes coercion, but for the guilty suspect it may be disadvantageous, since evidence already held by the police is not disclosed and the interviewee does not know what she needs to explain in order to establish innocence. In his final report to the UN General Assembly, the former Special Rapporteur on Torture, Juan Méndez, made a detailed call for an international protocol on investigative interviewing as an essential tool in torture prevention. ${ }^{28}$ The aim is something equivalent to the Istanbul Protocol on medical evidence of torture or the Minnesota Protocol on autopsies, which are widely perceived as setting the most advanced standards. Méndez's call precisely corresponds to our findings about the most effective protections for suspects in police custody.

\section{Investigation and prosecution}

The criminalization of torture, and the prosecution of those who commit the crime, has been the cornerstone of the international strategy for torture prevention for decades. The 1975 Declaration Against Torture, ${ }^{29}$ expanded and hardened into the 1984 Convention, made criminalization, investigation and prosecution the overriding priority. While the Convention does include other elements, such as the absolute prohibition on refoulement where there is a risk of torture, the rule excluding evidence obtained under torture, and the need for training and unspecified rules and procedures to prevent torture, it is, in the main structured as a crime prevention treaty.

It has long been held as axiomatic by anti-torture campaigners that the "cycle of impunity" is one of the main reasons for the persistence of torture, although there has never previously been a strong cross-country empirical underpinning for this belief. Some scholars have even associated ratification of the Convention with an increase in the incidence of torture. Our finding, to the contrary, was that ratification was weakly associated with a reduction in torture. (We found a similar weak negative correlation between incidence of torture and ratification of the Optional Protocol to the

\footnotetext{
${ }^{27}$ Asbjorn Rachlew, 'From interrogating to interviewing suspects of terror: Towards a new mindset (Prison Reform International, 14 March 2017) < https://www.penalreform.org/blog/interrogating-interviewingsuspects-terror-towards-new-mindset > accessed 10 August 2018

28 Interim report of the Special Rapporteur on torture and other cruel, inhuman or degrading treatment or punishment, 5 August 2016, A/71/298

${ }^{29}$ Declaration on the Protection of All Persons from Being Subjected to Torture and Other Cruel, Inhuman or Degrading Treatment or Punishment, UNGA Res 3452 (XXX) 9 December 1975
} 
Convention.) We assume it is not the ratification itself that reduces torture, but ratification may be evidence of the necessary political will to translate abstract commitments. Whether or not this assumption is correct, we note that those who argue that treaty ratification correlates with increased torture may be falling foul of a particular measurement fallacy, whereby the reporting obligations and increased scrutiny inherent in the treaty regime gives the impression of increased torture at a time when it is in fact decreasing. ${ }^{30}$

Our overall conclusion is that, when the Convention's requirements are actually implemented in practice, the long-standing view about the need to end impunity is precisely correct. As might be expected, the gap between law and practice is greatest in this area; almost all countries explicitly criminalize torture, yet the actual investigation, prosecution, conviction and punishment of torturers falls far short of the practice in relation to equivalent acts committed in a normal criminal context. The sad truth is that even the countries with best practice fall short of what the Convention requires. As with detention safeguards, none of the legal provisions that we looked at had any significant impact in reducing torture incidence merely by its presence in the statute book. However, several practice variables were of particular importance. Most relevant of all was simply whether complaints of torture were filed with the courts or the prosecuting authority in the first place, which goes to the overall credibility of the justice system. In many countries where there is serious torture, victims simply do not report this to prosecutors or investigators because they have no confidence in the impartiality and competence of the system. Another important factor is the likelihood of conviction. We considered whether those accused of torture had a chance of being convicted comparable to those accused of serious offences against the person in an ordinary criminal context. Equally important is whether the state granted amnesties or pardons for torturers, short-circuiting the whole process. When complaints are filed; when they are properly and independently investigated; when torturers are convicted; and when those convicted serve a full sentence without amnesty or pardon - then, the prosecution of torturers is a particularly effective way of preventing torture in the future.

\section{Monitoring places of deprivation of liberty}

Monitoring of places where there may be a risk of torture has increasingly been seen as the central strategy for preventing torture. Indeed, it is sometimes seen as being synonymous with torture

\footnotetext{
${ }^{30}$ A.M. Clark and K. Sikkink, 'Information Effects and Human Rights Data: Is the Good News about Increased Human Rights Information Bad News for Human Rights Measures?' (2013) 35 Human Rights Quarterly 539-68
} 
prevention, which is somewhat misleading, since safeguards that remove the opportunity to torture - such as ending incommunicado detention - seem more purely preventive. ${ }^{31}$ Nevertheless, the adoption of Optional Protocol to the Torture Convention (OPCAT), and in particular the creation of national preventive mechanisms, have indeed brought monitoring centre stage.

The origins of the strategy of "preventive monitoring" lie with the International Committee of the Red Cross (ICRC). Central to the ICRC's protective role have been monitoring visits to prisoners in wartime and, in some circumstances, also to security detainees outside conflict situations. Formed in the 1970 s by Geneva businessman Jean-Jacques Gautier, the Swiss Committee Against Torture advocated using the ICRC approach as a general strategy to prevent torture. In the course of the campaign for a UN convention against torture, it argued for an international monitoring body with the power to inspect places of detention and imprisonment. This was a step too far in the 1980s, but the proposal was picked up by the Council of Europe in its regional anti-torture convention, which led to the creation of the European Committee for the Prevention of Torture (CPT), whose primary function has been preventive monitoring. A decade or so later, debate on a proposed optional protocol to the UN Convention took an interesting turn. A number of countries from the global South took exception to the proposal for a global monitoring body and proposed instead that states parties should establish their own domestic monitoring bodies. The somewhat bizarre compromise adopted was to include both mechanisms in the OPCAT: a Sub-Committee on Prevention of Torture as a treaty body and national preventive mechanisms (NPMs) as domestic monitors..$^{32}$ In practice, the inclusion of NPMs has preserved the relevance of the OPCAT. Even though the SPT is the largest of UN human rights treaty bodies and the parties to the Optional Protocol remain relatively low in number - around 90 at the time of writing - the international body is scarcely able to fulfil its monitoring role.

In our study we did not only look at national preventive mechanisms or at international monitoring bodies established by treaty. The OPCAT is a relatively recent phenomenon, and one that still does not include the majority of states globally. However, across the entire three decades that we researched there were many other bodies with responsibility for inspecting or monitoring places where people were deprived of their liberty. Such bodies have sometimes been specialized focusing only on prisons, for example - and may not have been endowed with the full legal powers that an OPCAT-compliant NPM would now enjoy. These features were accounted for in our coding

\footnotetext{
${ }^{31}$ N.S. Rodley, 'Reflections on Working for the Prevention of Torture'

32 M. Evans and C. Haenni-Dale, 'Preventing torture? The development of the Optional Protocol to the UN Convention against Torture' (2004) 4 Human Rights Law Review 19-55
} 
scheme and allowed us to make a much broader assessment of the effectiveness of monitoring as a preventive measure.

As might be expected, the gap between law and practice scores was considerably less for monitoring than for either detention or prosecution. However, in the later years covered in our study a gap did appear. In the earlier years, a body tasked with monitoring would more or less fulfil its legal mandate. Later, perhaps, paradoxically, because of the OPCAT and the external pressure to establish monitoring mechanisms, the institutions that existed were on average less compliant with their legal obligations than in earlier years.

Again as might be expected, the most effective operational practice of monitoring mechanisms is that they actually conduct individual interviews with persons deprived of their liberty in the course of their visits; this might appear elementary, but some of the bodies that we studied did not do this. More surprisingly, legal immunity for monitors seemed to have no particular relationship to the effectiveness of a monitoring body. However, whether in practice monitors were able to go about their work without threat or interference emerged as the most important predictor of a body's effectiveness. Or conversely, threats, attacks or legal sanctions against monitors are an extremely effective and dangerous way of undermining the positive impact of a monitoring mechanism.

Our finding was that monitoring mechanisms clearly correlated with a reduction in the incidence of torture in the countries that we studied. However, the relationship was not as strong as either detention safeguards or prosecution of torturers. This conclusion does have to be qualified somewhat. First, we looked only at the impact of preventive measures on the incidence of torture, not on other forms of ill-treatment. It might be that if our focus had been broader, we would have reached a different conclusion. Secondly, there is clearly a close relationship between the role of monitoring bodies and the implementation of legal safeguards to protect detainees. If done properly, monitoring is not merely inspection of facilities but a serious probe into procedures and practices. Reports of the European CPT, for example, have generally been very effective in identifying systemic legal and practical failings. Hence monitoring is likely to remain an important element in a coordinated torture prevention strategy.

A common weakness of monitoring in the countries that we studied is that it tended to be focused overwhelmingly on the prison or penitentiary system rather than on those held in police custody. Yet torture is overwhelmingly more likely to take place in the latter setting - which is why detention safeguards were found to be so important. 


\section{Independent complaints mechanisms}

Independent, semi-formal complaints mechanisms have proliferated since the early 1990s. Their original model was the ombudsman institutions of Scandinavia and some Commonwealth countries, although these bodies were directed towards rectifying relatively minor cases of maladministration rather than serious violations of human rights. Since the 1980s there have emerged dozens of national human rights institutions with a specific mandate to examine complaints of violations without immediate recourse to either the criminal or civil justice systems. Most often these are human rights ombudsman institutions (primarily in central and eastern Europe and in Latin America) or national human rights commissions (in the Asia-Pacific region and Africa). These complaints mechanisms usually cover the full range of human rights issues, although some focus on specific institutional frameworks such as the prison system. In our study, we understood complaints mechanisms to refer to all these types of body, whether general ombudsman or national human rights institutions, or specific police or prisons ombudsman bodies. We did not understand it in this context to refer to complaints to the court or prosecutor.

It is argued that complaints mechanisms are an important part of the system that prevents torture. Our research found little evidence to support this contention.

Why might complaints mechanisms not be a particularly effective means of preventing torture? It seemed to us that ombudsman-style complaints procedures have all the disadvantages of the prosecutorial system when it comes to investigating torture allegations and none of the advantages. The principal disadvantage, from the perspective of the torture victim, is that the act of making a complaint creates further jeopardy for the complainant. As we have seen, the whole prosecution mechanism most often falls at the first hurdle, with victims declining even to lodge a complaint of torture. However, if a victim perceives some possibility that a complaint will result in further action against the perpetrators, then he or she may be willing to take this risk. In the case of a semi-formal, ombudsman-style complaints mechanism, which has no binding power to secure a prosecution even if it finds in the complainant's favour, then lodging a complaint looks like a very poor gamble.

This interpretation is made more likely by a parallel finding of ours. Several of the complaints mechanisms in our study are organically linked to the prosecutorial process. Bodies such as the Northern Ireland Police Ombudsman, the Independent Office for Police Conduct in England and Wales, and the Independent Police Investigative Directorate in South Africa are essentially a much more accessible route into the prosecutorial system, with the complaints bodies required to refer any finding of torture to the prosecutors. In these instances, we found that such mechanisms do appear to be associated with reduced incidence of torture. 


\section{Law and practice}

A common thread through our country case studies, as well as in the quantitative findings, is the significant gap between law and practice. There is not a single legal mechanism that is strongly correlated with a decrease in torture. It is only when laws are put into practice that they have their effect in reducing torture. This seemed to us a commonsensical finding although some (usually lawyers!) have disagreed. Of course, legal reform is important because it usually, although not invariably, precedes improvement in practice.

The gap between law and practice, as we have indicated, is greatest in relation to investigation and prosecution of torturers, where no country has a particularly impressive record, even though all criminalize torture to some extent. It is smallest in relation to complaints and monitoring where institutions established in law usually do a reasonable job of executing their functions. Most importantly, there remain significant gaps between the legal safeguards for detainees or suspects and the actual protection that they enjoy in custody.

The precise reasons for these gaps will vary. There may well be a general disinclination on the part of police to comply with rules that they see as unduly favouring suspects and their readiness to do so will be determined by levels of corruption, discipline and professionalism. But there are other contextual factors that are not necessarily the fault of the detaining authority. We have indicated that many countries lack the professional personnel - such as lawyers or doctors - to make these safeguards a reality.

Training is a potentially important way of bridging the gap between law and practice. We measured the impact of training in relation to investigative and custodial personnel, as well as for judges, prosecutors, monitors and complaints handlers. Training clearly does have a positive effect, according to our findings. In addition, our finding about reducing the reliance on confession evidence needs to be understood in conjunction with this. Training that enhances the professional capacities of the police can play a very important part in reducing the risk of torture.

\section{Three case studies}


As further illustration of our findings, below we discuss three of our country case studies in further detail. ${ }^{33}$ Both the United Kingdom and Turkey are strong examples of the positive impact of improved detention practice, which followed positive legal reforms in criminal procedure. The difference is that in Turkey a collapse of political will (and the persistence of impunity) has resulted in the serious recurrence of torture. Argentina also saw a substantial decrease in torture after the fall of its military dictatorship, but improved detention safeguards were never translated into practice. Police indiscipline and impunity have allowed torture to persist.

\section{United Kingdom ${ }^{34}$}

The United Kingdom presented the clearest example in our study of a state that had effected a major and sustained reduction in the incidence of torture. Economically developed democracies are generally less disposed towards the use of torture than either poor countries or autocracies, but it is easy to forget that in the 1970s, before the start of our study period, the UK had a serious torture problem. This was most famously associated with counter-insurgency policies in Northern Ireland, where British treatment of prisoners was the subject of an inter-state complaint at the European Court of Human Rights. ${ }^{35}$ Equally famously, the Court found that the sensory deprivation techniques used on Irish nationalist prisoners amounted "only" to inhuman or degrading treatment - a decision most unlikely to find favour today. Torture was endemic in the behaviour of the security forces in Northern Ireland up until the 1990s, although never again quite reaching the same pitch of atrocity as the 1970s. However, the problem was not confined to these political cases. Many of Britain's decentralized police forces regularly resorted to threats, coercion and worse in their treatment of criminal suspects. While human rights campaigners warned of how police in mainland Britain might acquire repressive techniques from their Northern Ireland counterparts, the arrow often pointed in the other direction. One of the great causes celebres for the civil liberties campaigners of the period was the case of the Birmingham Six - Irish residents of the Midlands city wrongfully convicted of planting a bomb in a bar, killing 21 people. This was one of a number of serious miscarriages of justice in this period. The case was investigated by a unit called the West Midlands Serious Crimes Squad, which tortured confessions out of some of the Six. Yet, while there was no doubt a particular anti-Irish animus in this case, this was actually the way that this unit regularly handled cases. ${ }^{36}$ They

\footnotetext{
${ }^{33}$ All three of these countries were included in the pilot stage of the research, which meant that the authors of this chapter were directly involved in the field research.

${ }^{34}$ A full discussion of the UK case study is to be found in R. Carver, "United Kingdom" in Carver and Handley, Does Torture Prevention Work? pp. 105-42.

${ }^{35}$ Ireland v. United Kingdom, (no 18/01/1978) (1978) Series A no 25

${ }^{36} \mathrm{~T}$. Kaye, Unsafe and Unsatisfactory? The Report of the independent inquiry into the Working Practices of the West Midlands Serious Crime Squad. London: Civil Liberties Trust, 1991.
} 
often inflicted beatings and near suffocation with plastic bags, resisting reforms until the unit had to be wound up in 1989. Twenty-five years after the squad's dissolution, the courts were still handling the aftermath of its torturous practices. ${ }^{37}$

The main response to the slew of miscarriages of justice and consequent public disquiet was a radical review of criminal procedure. Given that this was initiated by the Conservative government of Margaret Thatcher, it was greeted with great scepticism by civil libertarians. Yet, in retrospect, it is clear that the Police and Criminal Evidence Act 1984 (PACE) has resulted in dramatic improvements to the safety of people taken into police custody. ${ }^{38}$ As discussed above, arguably the most important of the PACE innovations was the creation of a state-funded duty solicitor scheme. This ensured that criminal suspects had permanent 24-hour access to a defence lawyer in private practice. The scheme is such that, even if an individual decides not to avail themselves of the right to a lawyer, there will most likely be other lawyers present at the police station, at least at busy stations and at busy times.

Many of the PACE safeguards, such as the right to prompt consultation with a lawyer, already existed under the common law, but their codification in statute law proved very important. There are PACE Codes that give practical and detailed guidance to police officers on issues such as notification of family or friends, presentation before a judge, and medical examinations. PACE also provided new rules on the conduct of interviews with suspects, making audio (and later video) recording mandatory. This triggered a more widespread review of interviewing, with an increased focus since the early 1990s on investigative interviewing, with the purpose of fact-finding rather than securing confessions, as noted previously. ${ }^{39}$ This fits with our overall observation that a reduced reliance on confession evidence leads to a lower incidence of torture.

PACE is not perfect; one of its continuing weaknesses is that certain guarantees are weakened or suspended in cases involving terrorist offences. Detention conditions for terrorist suspects undoubtedly remain much more oppressive than for ordinary criminals. However, the intense public scrutiny of such cases has, at least since the end of the Northern Ireland conflict, provided some protection.

\footnotetext{
${ }^{37} R v$ The Director Of Public Prosecutions ex parte Treadaway [1997] High Court QBD (Divisional Court); $R v$ Keith Twitchell [2000] 1 Cr.App.R. 373; R v Foran [2014] EWCA Crim 2047

${ }^{38}$ Versions of the same legislation were enacted in the distinct jurisdictions of Northern Ireland and Scotland in 1989 and 1994 respectively.

${ }^{39}$ A. Shawyer, B. Milne and R. Bull, 'Investigative Interviewing in the UK' in T. Williamson, B. Milne and S.P. Savage (eds), International Developments in Investigative Interviewing (Routledge, Abingdon 2009)
} 
The treatment of prisoners in Northern Ireland, where the worst torture took place, was improved in part by the application of the PACE standards. The decisive change, however, came with the political settlement leading to the 1998 Belfast (or Good Friday) Agreement. Among the outcomes was the creation of a completely new Police Service of Northern Ireland to replace the Royal Ulster Constabulary, which had been deeply implicated in torture and ill-treatment of political prisoners. Equally important was the creation of new civilian oversight bodies: a Northern Ireland Policing Board that, among other things, has a statutory responsibility to ensure police compliance with the Human Rights Act; and a Police Ombudsman that investigates complaints against the police. The Police Ombudsman is extremely well resourced, has access to an independent forensic service, and can investigate criminal cases against the police and refer them directly to the prosecutorial authorities.

The effectiveness of police reform in Northern Ireland contrasts with the experience of most of the countries we studied. Out of the 16 , almost all had experienced some sort of political transition over the 30-year period covered by our study, whether from conflict to peace or from authoritarianism to democracy. Yet only one country, Georgia, undertook radical police reform of the type implemented in Northern Ireland. Demilitarization of the police in Indonesia may have played an important part in the reduction of torture, but countries like South Africa had only imperfect or incomplete reform, while Argentina (see below) scarcely addressed the issue at all.

Turkey ${ }^{40}$

It is a commonplace that political will is necessary to tackle the problem of torture. Turkey provides a very clear example of what political will can achieve - and what happens when that will evaporates. It also is an interesting case study in how the requisite political will achieves its objectives through preventive mechanisms.

In the 1980s and 1990s the incidence of torture in Turkey was at critically high levels. Torture occurred both in the context of a brutal counter-insurgency campaign in the Kurdish areas of the country and as part of the regular functioning of the criminal justice system. There was no significant attempt to address this problem until the very end of the 1990s. Four developments contributed to generating the political will to do something about torture. First, there was a change of government, with a left-leaning coalition led by Bülent Ecevit more inclined to address the problem. Secondly, Turkey formally applied for membership of the European Union, which comes with heavy human rights conditionality. Thirdly, the Parliamentary Human Rights Commission was very active in

\footnotetext{
${ }^{40}$ Full details of the Turkey case study are in K. Altiparmak, R. Carver, and L. Handley, "Turkey" in Carver and Handley, Does Torture Prevention Work? pp. 439-68.
} 
exposing torture and poor detention practices, with frequent unannounced visits to prisons and places of detention - an interesting example of the potential impact of monitoring on other preventive measures. Fourthly, the 1999 capture of the Kurdish insurgent leader Abdullah Öcalan led to a distinct winding down of the armed conflict and a gradual lifting of emergency powers.

Our research suggested that by the time Ecevit handed over the premiership to Abdullah Gül of the newly elected Justice and Development Party (AKP), in 2002, there had been a discernible decline in the incidence of torture. Where torture continued, it appeared to be less severe than previously. This improvement continued throughout the first decade of the century.

The principal reason behind the decline in incidence of torture appears to have been substantial and successive improvements in detention safeguards to bring them into line with European standards. One of the consequences of the highly centralized and disciplined Turkish state system was that legal improvements were rapidly translated into practice. This was reinforced by clear public statements condemning torture on the part of successive governments.

The effort to reduce torture was also helped by the acquisition of alternative techniques of criminal investigation. These included extensive electronic surveillance powers that raise their own human rights issues. This problem notwithstanding, it is clear that, in the words of one civil society monitor: "Previously the police would reach evidence through the accused; now they reach the accused through evidence." ${ }^{41}$

The aggressive monitoring conducted by the Parliamentary Commission in the late 1990s proved to be an exception. The Commission's chairperson during this period was even threatened with suspension of parliamentary immunity to force her to reveal the names of those who alleged torture. Thereafter this parliamentary body became less independent and was seriously weakened. A network of official Human Rights Boards, created in 2001, proved notably ineffective in either monitoring or complaints-handling. The later creation of a national human rights institution and an ombudsman office has barely improved matters when it came to questions of ill-treatment or torture.

Equally, the investigation and prosecution of the crime of torture was almost non-existent. Although there were various legal reforms from 1999 onwards - increasing and later abolishing the statute of limitations for torture, repealing obsolete laws protecting public officials from investigation - the

\footnotetext{
${ }^{41}$ K. Altiparmak, R. Carver and L. Handley, Turkey
} 
actual investigation of torture cases has been limited, convictions extremely rare, and penalties derisory.

Turkey provides a case study that illustrates very clearly our contention that detention safeguards constitute the most effective preventive mechanism - for the simple reason that none of the other mechanisms even existed to a significant degree. Sadly, the Turkish case also demonstrates how political will is a highly changeable factor. By the end of our study period, the increase in popular protest against the AKP government was being met with an increase in police violence and illtreatment. An alleged coup attempt in 2016 resulted in a full-blown return to the 1990s. National security overrides that had never been fully abolished came into effect and there was mass torture of so-called Gülenists - essentially a broad spectrum of the government's political opponents.

\section{Argentina $^{42}$}

Argentina is often held up as a positive example. Specifically, it is claimed that "transitional justice" has contributed to the consolidation of democracy and a more solid protection of human rights. ${ }^{43}$ Our research in Argentina suggests a much more complex picture, at least in relation to torture. While torture and other gross human rights violations are not remotely comparable to the situation under the military dictatorship that ended in 1983, neither has torture disappeared. In the 35 years since the end of the dictatorship, justice against military human right violators has been pursued unevenly, but nevertheless on a scale that is relatively unusual. Yet this appears not to have deterred present-day torturers because they are different actors - police, not military - inflicting ill-treatment on different victims - poor urban youth, not middle-class political dissenters. ${ }^{44}$ To the extent that torture in Argentina has reduced, this has been primarily the consequence of improved safeguards at the time of arrest. To the extent that it continues, this is because of the police sidestepping the safeguards, and doing so with impunity.

The fall of the military dictatorship led to an immediate decline in the incidence of torture because the new democratic administration was not repressing its political opponents. The first postdictatorship government, led by Raúl Alfonsín, introduced reforms to protect suspects in the early hours and days after arrest, most importantly reducing the limit for incommunicado detention from 30 to three days. Further proposed reforms did not win sufficient congressional support and it was

\footnotetext{
${ }^{42}$ The Argentina case study was not included in Does Torture Prevention Work? although the data gathered was included in our quantitative analysis.

${ }^{43}$ See, for example K. Sikkink and C.B. Walling, 'The Impact of Human Rights Trials in Latin America' (2007) 44 Journal of Peace Research 427-45; K. Sikkink, The Justice Cascade: How Human Rights Prosecutions Are Changing World Politics (W.W. Norton, New York 2011)

${ }^{44}$ F. Lessa, 'Beyond Transitional Justice: Exploring Continuities in Human Rights Abuse in Argentina between 1976 and 2010' (2011) 3 Journal of Human Rights Practice 25-48
} 
not until 1991, under Alfonsín's successor, Carlos Menem, that a rather weaker package of laws was enacted. These included immediate notification of family or friends for anyone arrested without a warrant and a provision that suspects could only be directly interrogated by a judge, not by the police.

The problem was that, although the legal reforms undoubtedly pointed in the right direction, the police effectively operated as a law unto themselves. Partly this was simply a consequence of decentralization. Argentina is a federal state with 24 police forces -23 provincial and one federal. The contrast to Turkey, with twice the population but a single police chain of command, is striking. Even more importantly, the police were subject to no systematic reform after the fall of the military dictatorship. The military had been primarily responsible for human rights abuses under the junta and were hence the priority for reform. Alfonsín's attempts to initiate reform in the 1980 s - to restructure the police, restrain corruption, and create external accountability - came to nothing. By the 1990s, politicians were competing to advocate "iron fist" responses to crime. Most bizarrely, the police even fabricated crimes in order to get the credit for solving them ${ }^{45}$ - yet still there has been no effective move to hold them accountable.

The public dramatization of the threat of crime has allowed the police to get away with corruption and torture, as in other countries in our study such as South Africa. The paradox, of course, is that non-corrupt police that used proper investigative methods, rather than beating confessions out of suspects, would deal with crime much more effectively. Nevertheless, these attitudes have allowed the police to get away with ignoring detention safeguards. They have also exploited legal loopholes, such as the fact that a person may be detained for up to 10 hours for the purposes of identification, without triggering the right to a lawyer. Buenos Aires police conduct roundups of poor youth, ostensibly for the purposes of identification but in reality to commit acts of violence against them.

Despite the picture of Argentina as a country where human rights violators are held criminally accountable, in reality the police enjoy almost total impunity for torture and ill-treatment. Victims are in fear and extremely reluctant to lodge complaints. Even when complaints are filed, these are not systematically investigated. And cases that do finally make it to court are frequently reclassified as lesser offences (a phenomenon we observed in many countries).

None of this is mitigated by effective monitoring or complaints mechanisms. Again, the federal structure is a large problem, with a patchwork of national and provincial mechanisms creating some overlaps and many gaps. In some instances, activists at the provincial level have been able to turn

\footnotetext{
${ }^{45}$ Interview with Judge Daniel Rafecas, Buenos Aires, June 2013
} 
federalism to their advantage and create reasonably effective "provincial preventive mechanisms," but this is the exception rather than the rule. In any event, it is difficult to see what monitors or complaints-handlers would bring to a situation where the problem has been clearly diagnosed in many reports by national, regional and international bodies: a continuing culture of impunity and police lawlessness.

\section{Conclusion}

Our study found a gradual decline in torture over 30 years in the 16 countries that we examined, attributable at least in part to the impact of preventive mechanisms and especially to the practical observance of detention safeguards.

Discussion of the problem of torture tends to focus too much on political cases, in particular counter-terrorism and thought experiments such as the "ticking-bomb" scenario. Yet, these discussions are largely irrelevant since such cases represent a tiny fraction of the global incidence of torture. Most instances of torture occur in the context of dysfunctional criminal justice systems. Police are undereducated, undertrained, underpaid and corrupt. They lack the skills to investigate crime and yet are under political and public pressure to deliver results. (In one country that we studied, torture tended to increase towards the end of the month when prosecutors struggled to deliver their quota of indictments.) Provisions to provide legal representation or medical examinations do not work because there is no one to deliver these services. Complaints of torture are not properly investigated, either because there is no independent body to conduct the investigation or because there is no will to do so, or both. Detention safeguards will achieve the desired effect of dramatically reducing torture, but only if fully implemented in practice. This in turn requires both resources and political will. Argentina and Turkey are both examples of how political will can very rapidly dissipate.

If the overall conclusion is that torture prevention measures do work, the paradox is that those that work most effectively are those that are least strongly supported in international law. Prosecution of torturers and monitoring mechanisms are both important in preventing torture and are underpinned by global (and regional) treaties. At a global level, detention safeguards only exist in hard law to the extent that they overlap with fair trial provisions. The UN Body of Principles for the Protection of All Persons under Any Form of Detention or Imprisonment ${ }^{46}$ provides more extensive protections, for

\footnotetext{
${ }^{46}$ Body of Principles for the Protection of All Persons under Any Form of Detention or Imprisonment, UNGA Res 43/173 9 December 1988
} 
example in relation to notification of a third party on arrest and the right to a medical examination. But even here, in this soft law instrument, the right to a lawyer is framed weakly and sometimes negatively: it may not be "suspended or restricted save in exceptional circumstances." There is no mention that this right should be available promptly upon arrest. ${ }^{47}$ The reason, of course, is that many national legal systems - particularly those based upon the French and Spanish codes - make exclusion of legal counsel a positive feature of the early days of the investigation. While regional bodies such as the European Court of Human Rights are increasingly addressing this problem, the global diffusion of these legal norms will take much longer effort to unravel.

${ }^{47}$ N. Rodley, The Treatment of Prisoners under International Law (3rd edn Oxford University Press, Oxford 2009) 